\title{
Electrochemical Study of MoTaNbVTi High Entropy Alloy in Aqueous Environments
}

\author{
Anthoula Poulia*, Christina Mathiou, Alexander Karantzalis \\ Department of Materials Science and Engineering, University of Ioannina, Ioannina, 45110, Greece
}

Corresponding Author Email: apoulia@uoi.gr

https://doi.org/10.18280/acsm.430401

Received: 12 May 2019

Accepted: 26 July 2019

\section{Keywords:}

electrochemistry, hank solution, high entropy alloys, sea water solution

\begin{abstract}
The purpose of this study is to investigate the corrosion behavior of MoTaNbVTi refractory high entropy alloy in $3.5 \mathrm{wt} . \% \mathrm{NaCl}$ and Hank solution. Regarding the sea water testing environment, data from the electrochemical analysis of the polarization curves created some first suspicions about a local corrosion tendency. However, the corroded surfaces and crosssections' Scanning Electron Microscopy and Energy Dispersive Spectroscopy analysis verified no signs of any type of degradation. Moreover, the results indicate that no selective corrosion along the inter-dendritic regions of the alloy, was found. As far as the Hank solution is concerned, once again, some preliminary considerations of a possible susceptibility to local forms of corrosion were shown off, however, no evidence of corrosion signs (either pericrystalline or pitting) was detected. The findings of this research suggest that MoTaNbVTi presented an excellent response to these types of corrosion environments and could be used as an ideal candidate for that kind of applications.
\end{abstract}

\section{INTRODUCTION}

Metallic materials and alloys are of great scientific and industrial importance, therefor they attract significant literature interest. During the last years, a novel introduction in metallic alloys, namely High Entropy Alloys (HEAs), has changed the, so far, well-established theories of metallic materials [1]. Due to their multi-component character [2], HEAs present special microstructural features and properties $[3,4]$.

HEAs have been reported with high hardness and high compressive strength, both at room temperature and at elevated temperatures [5-7]. They have also been reported to possess outstanding wear $[8,9]$ and oxidation $[10,11]$ resistance, as well as high thermal stability [12]. However, the researches on corrosion resistance are comparatively rare. Most of the work on this field has been conducted in transition HEAs tested in aqueous solutions [13, 14], while work on refractories still remains scant [15].

In more details, a number of investigations on the corrosion behavior of HEAs revealed equivalent or superior corrosion resistance of HEAs in various aqueous environments, as compared with conventional corrosion-resistant alloys [16]. However, electrochemical data also need to be comprehended, on the basis that HEAs have the intention to segregate and consist of various phases (of widely different compositions), and do not follow the conventional formulas of the wellknown metallic materials, such as stainless steels and other alloys [17].

The purpose of this study is to investigate, for the first time, the electrochemical polarization behavior of MoTaNbVTi refractory high-entropy alloy, in two different corrosion environments. This work is believed to significantly contribute to the understanding of the complicated nature of this system, regarding its corrosion response.

\section{EXPERIMENTAI}

MoTaNbVTi refractory high entropy alloy was synthesized by means of vacuum arc melting in its equiatomic composition. Data regarding its microstructure and crystal structure were thoroughly presented in [18]. Here, the alloy's behavior was evaluated in two aqueous corrosive environments, namely 3.5 wt. \% $\mathrm{NaCl}$ and Hank solution with a chemical composition as tabulated in Table 1.

Table 1. Chemical composition of Hank solution

\begin{tabular}{cc}
\hline Components & Quantity (g/L) \\
\hline Calcium chloride (anhydrous) & 0.11168 \\
\hline Magnesium sulfate (anhydrous) & 0.16 \\
\hline Potassium chloride & 0.32 \\
\hline Potassium phosphate (anhydrous) & 0.048 \\
\hline Sodium chloride & 6.4 \\
\hline Sodium phosphate (anhydrous) & 0.48 \\
\hline D-Glucose & 0.8 \\
\hline
\end{tabular}

Circular potentiodynamic polarization tests, were conducted using a GillaC Weld 1315 galvanostat from ACM Instrument with a three electrode cell $(\mathrm{Ag} / \mathrm{AgCl} / 3.5 \mathrm{M} \mathrm{KCl}$, $\mathrm{Pt})$. The testing parameters were: 2 hours of immersion under open circuit to reach steady state; circular polarization condition in potential range of $-1000 \mathrm{mV}$ to $+1500 \mathrm{mV}$ and a scanning rate of $10 \mathrm{mV} / \mathrm{min}$. Three repeating trials in each solution were performed.

Circular polarization voltammograms of the corrosion potential as a function of the current density were constructed in each case, so as to determine the corrosion kinetics (using Tafel equations) and the corrosion potential values. Further analysis on the corrosion mechanisms was provided by the examination of the corroded surfaces and cross-sections via Scanning Electron Microscopy (JEOL 6510 LV) equipped 
with both backscatter electron (BSE) and energy dispersive spectroscopy (EDX) detectors.

\section{RESULTS}

\subsection{Corrosion behavior of MoTaNbVTi HEA in 3.5 wt. \% $\mathrm{NaCl}$ solution}

After completing the tests of circular potentiodynamic polarization, the most representative curve is presented in Figure 1. This figure also records the potentials of the forward and the reverse polarization, as well as the breakaway potential. As observed from the shape of the curve, the alloy is susceptible to local corrosion, since the reverse polarization curve returns to the right side of the forward, i.e., to higher current density values. However, for very high current density values, a small positive hysteresis loop is formed, but then the appearance of a large negative loop is obvious.

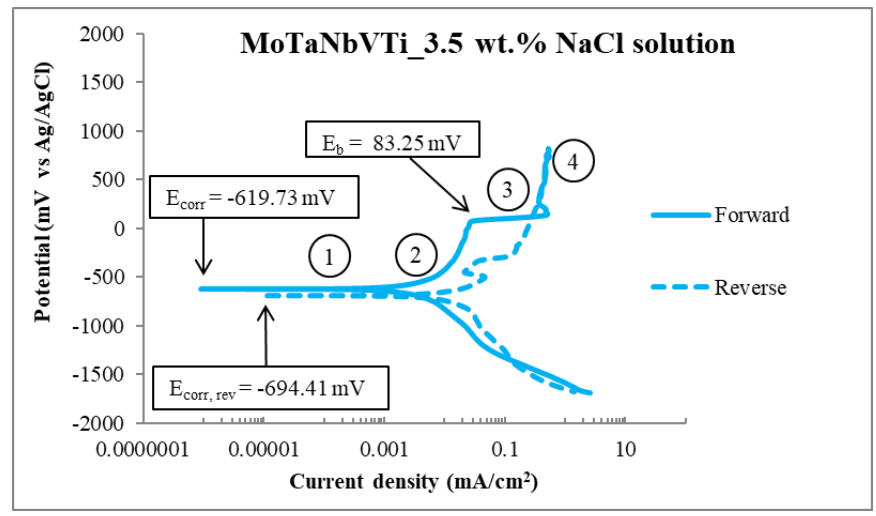

Figure 1. MoTaNbVTi's circular potentiodynamic polarization curve in sea water solution. The corrosion potential of the forward polarization, $\mathrm{E}_{\text {corr }}$, the reverse polarization, $\mathrm{E}_{\mathrm{corr}}$ rev, and the breakaway potential, $\mathrm{E}_{\mathrm{b}}$, are recorded. The stages of the anodic part are also marked

The corrosion potential of the reverse polarization, $\mathrm{E}_{\mathrm{corr}, \mathrm{rev}}$, is less noble (i.e. more negative values) than the corrosion potential of the forward polarization, $\mathrm{E}_{\mathrm{corr}}$, which indicates that the alloy's surface on the reverse polarization is probably less noble than that of the forward one, resulting in the alloy possibly being susceptible to pitting corrosion.

Continuing with a more detailed examination of the circular potentiodynamic polarization curve, it is worth focusing on the anodic part of the forward polarization, which can provide further information on the corrosion mechanism taking place, as the potential increases. More specifically, the presence of four distinct stages is evident in this part of the curve. In stage 1 active corrosion takes place, while in stage 2 the current density tends to stabilize over a wide range of potentials. After the breakaway potential, $\mathrm{E}_{\mathrm{b}}$, follows stage 3 where a sharp increase in current density is observed for more than two orders of magnitude at constant potential values. Finally, in stage 4 the current density is once again stabilized at very high values, which can be attributed to the formation of unstable corrosion products on the alloy surface.

During reverse polarization in stage 4 , the hysteresis loop initially created is positive. However, in stage 3 , the loop becomes negative, indicating that the pits of stage 4 which were initially covered with unstable corrosion products, in this case seem to be re-activated.
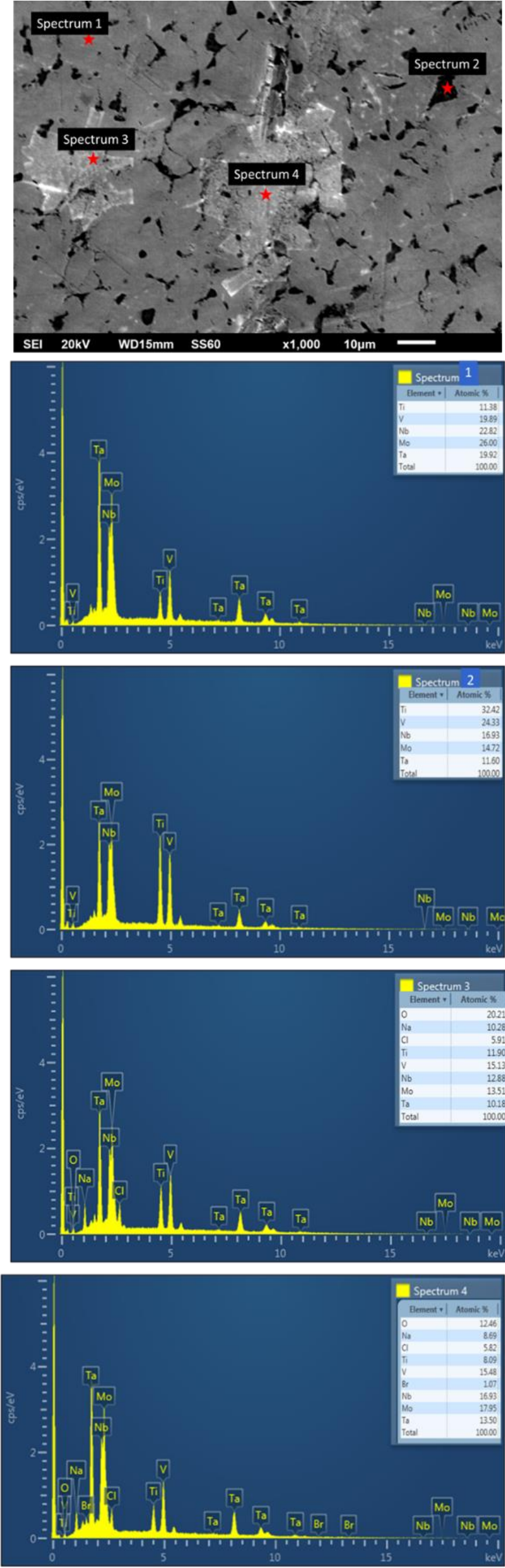

Figure 2. Scanning Electron Microscopy image and elemental point EDX analysis of the surface of the corroded MoTaNbVTi system in 3.5 wt.\% $\mathrm{NaCl}$ aqueous solution 
In any case, to enhance these first observations based on electrochemistry, the study of the surfaces and cross-sections of the corroded system was conducted via Scanning Electron Microscopy and corresponding quantitative EDX analysis. Thus, Figure 2 presents the surface of the corroded MoTaNbVTi system in $3.5 \mathrm{wt} \% \mathrm{NaCl}$ solution, as well as the results of the point elemental analysis in various points.

Primarily, it can be seen that the surface of the sample does not appear to be affected at all by the presence of the corrosive medium, as both the main body of the dendritic areas (Spectrum 1) and the inter-dendritic areas (Spectrum 2) are only characterized by the five alloying elements of the studied system and not any of the corrosive elements (salts or oxides). However, the formation of some oxidized layers of sodium chloride salts (Spectrum 3 and Spectrum 4) is found in individual areas of the surface (covering both the dendritic arms and the inter-dendritic space). This fact indicates that the alloy showed no signs of severe corrosion, while some residues of the corrosion solution simply covered its surface. As such, the observation of the sample does not reveal any selective galvanic inter-dendritic corrosion as recorded in other systems of the literature [19-24].

In addition, the quantitative mapping EDX analysis of Figure 3 also confirms the presence of sodium chloride on the surface of the sample in the form of a grid developed in random sites.

Regarding the observation of the cross-section of the sample under sodium chloride environment, as shown in Figure 4, the signs of corrosion did not penetrate into the material as both the dendritic areas (see Spectrum 2) and the inter-dendritic space (see Spectrum 3) have no traces of corrosion, that is, no chlorine ions confirmed their interaction with the alloy to be tested.

On the contrary, only at the edge of the cross-section does it appear that a surface film of oxides enriched with small amounts (about 7-8 at.\%) of the constituent elements (and not by the chloride ions) was detected. These findings are also confirmed by the quantitative analysis of the sample's crosssection, as shown in Figure 5.

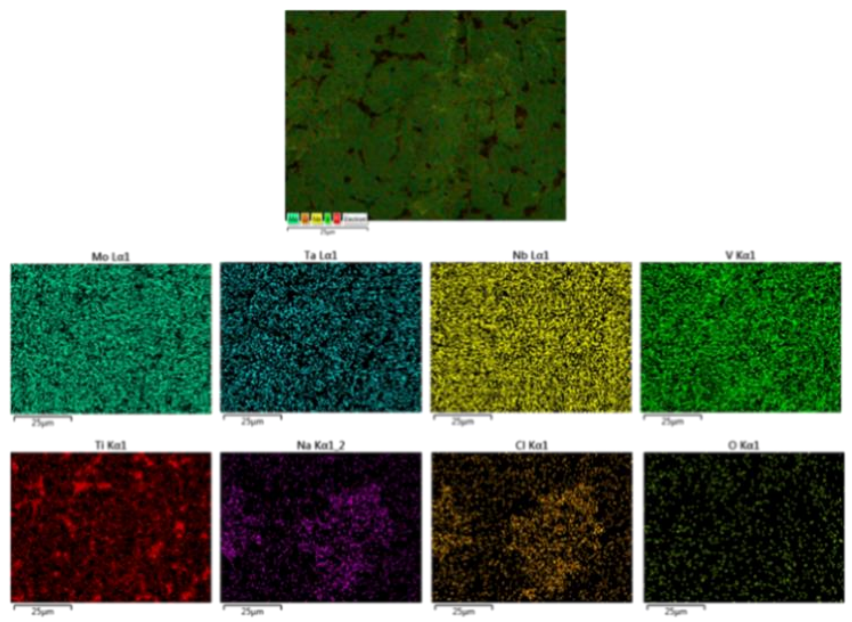

Figure 3. Quantitative EDX mapping analysis of the surface of the corroded MoTaNbVTi system in 3.5 wt. $\% \mathrm{NaCl}$ aqueous solution
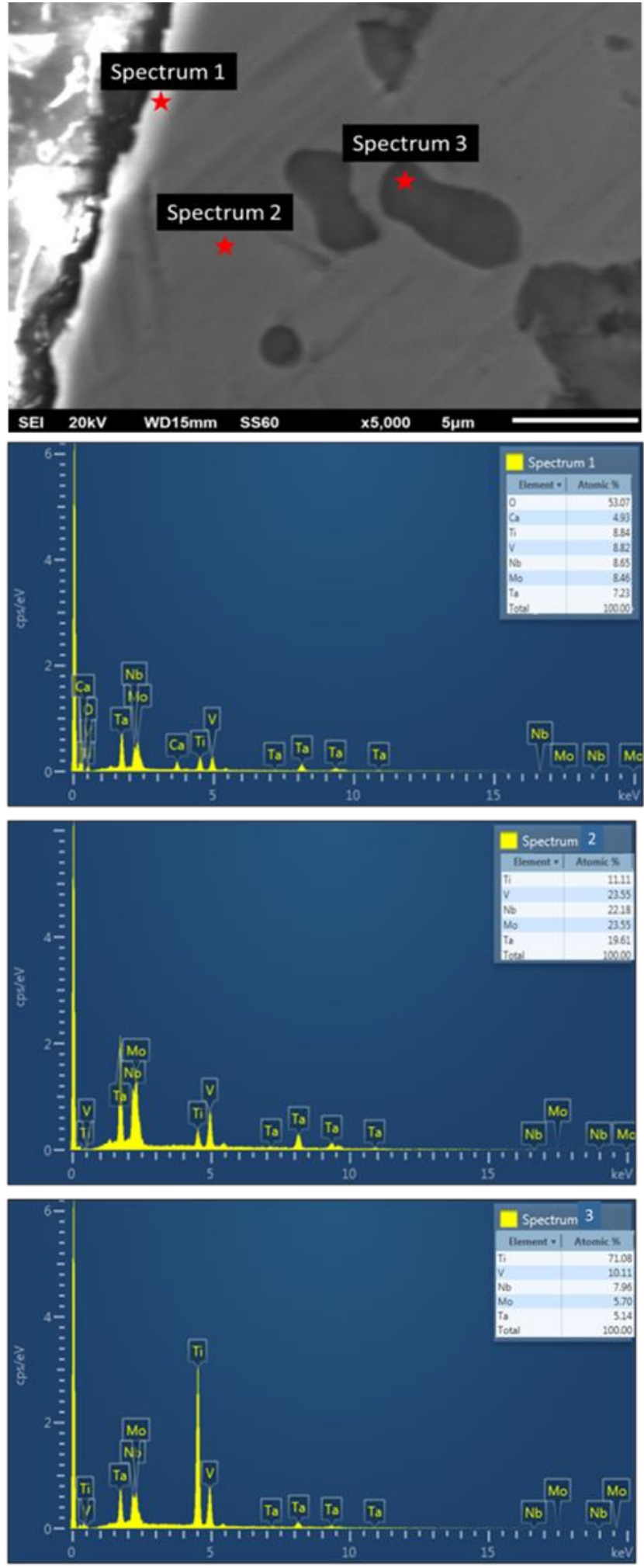

Figure 4. Scanning Electron Microscopy and corresponding point elemental EDX analysis on the cross-section of the corroded MoTaNbVTi system in 3.5 wt.\% $\mathrm{NaCl}$ aqueous solution 

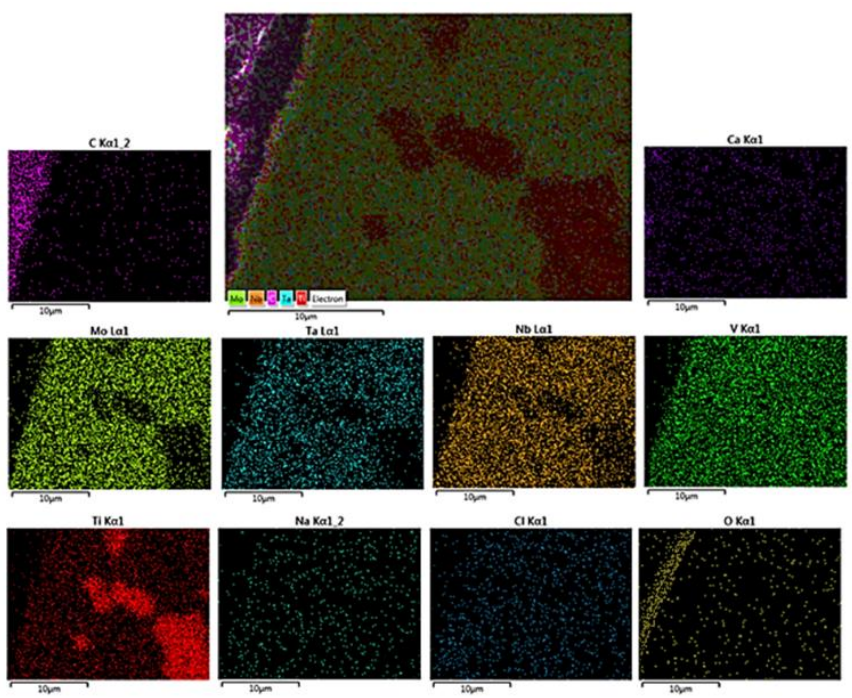

Figure 5. Quantitative EDX mapping analysis of the crosssection of the corroded MoTaNbVTi system in $3.5 \mathrm{wt} . \%$ $\mathrm{NaCl}$ aqueous solution

\subsection{Corrosion behavior of MoTaNbVTi HEA in Hank solution}

Figure 6 presents the most representative voltammogram of MoTaNbVTi HEA, when tested in Hank solution. The values of the corrosion potential for the forward and the reverse polarization are marked. As shown in the diagram, a small negative hysteresis loop appears, as the reverse polarization curve returns to slightly higher current density values than the forward polarization. In addition, the corrosion potential of the reverse polarization is less noble (more negative) than that of the forward polarization, indicating that the surface area of the alloy in reverse polarization, is less noble than that in the forward polarization.

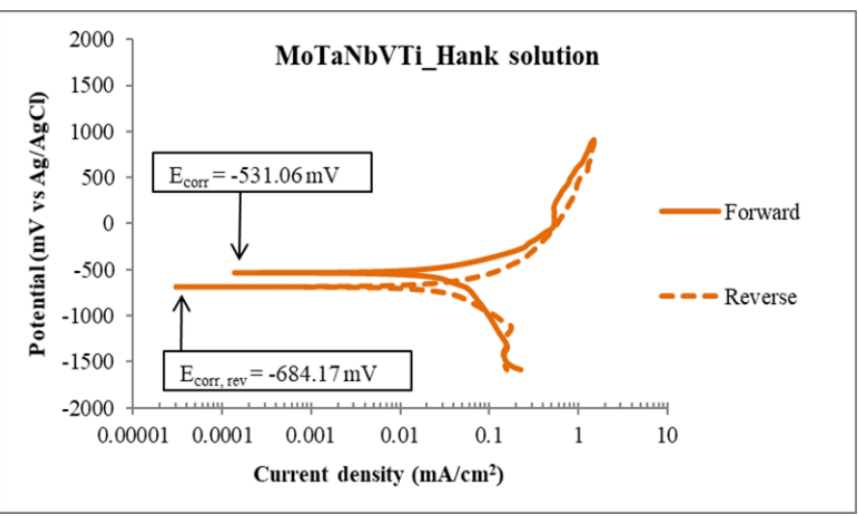

Figure 6. MoTaNbVTi's circular potentiodynamic polarization curve in Hank solution. The corrosion potential of the forward polarization, $\mathrm{E}_{\mathrm{corr}}$, and the reverse polarization, $\mathrm{E}_{\mathrm{corr}, \text { rev }}$, are recorded

These two observations raise some initial speculations about the possible susceptibility of the studied alloy to local forms of corrosion, however, due to the small extent of the negative hysteresis loop, further study of the anodic part of the forward polarization is required. Thus, in the anodic part of the forward polarization curve a fairly large area of active corrosion is initially recorded, and the current density increases linearly at large values (about three orders of magnitude), for a range of low potentials. At this stage the active dissolution of the constituents of the alloy takes place, during which the material corrodes.

In the next step, the current density tends to be stabilized over a small range of potentials, while finally there is an area that appears closer to the larger recorded current density values, in which a decrease in the current density's increasing rate is being marked.

In general, it could be said that the evaluation of electrochemical data cannot clearly interpret the proposed corrosion mechanism of the alloy and in any case further study of the corroded surfaces and cross-sections of the sample is required.
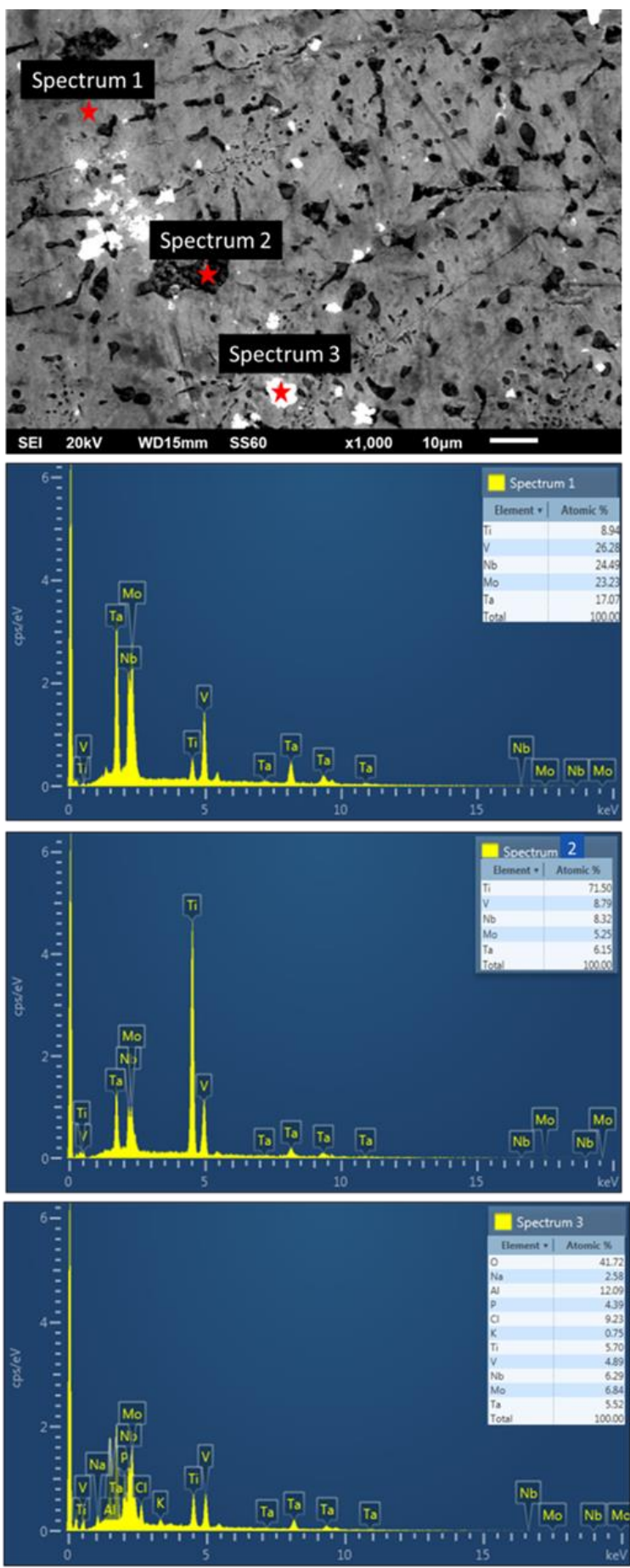

Figure 7. Scanning Electron Microscopy image and elemental point EDX analysis of the surface of the corroded MoTaNbVTi system in Hank solution 
Thus, Figure 7 presents the surface of the tested alloy by means of Scanning Electron Microscopy and the corresponding EDX point analysis at selected points of interest. The surface of the alloy both in the area of the dendritic arms (Spectrum 1) and in the inter-dendritic space (Spectrum 2) does not appear to have any signs of corrosion, since no sufficient amount of oxygen was detected at these sites. On the contrary, some white areas (Spectrum 3) have been found, which appear to be deposited residues of the Hank corrosive solution. These particles have a high oxygen content (about 40 at.\%), small percentages of the HEA's constituent elements (about 4-6 at.\%), while the rest of them consist of elements derived from the Hank solution (e.g. $\mathrm{Al}, \mathrm{P}$ and $\mathrm{Cl}$ ).

The above observations are further supported by the data in Figure 8 of the quantitative analysis of the surface of the corroded MoTaNbVTi system in Hank solution. The absence of pericrystalline corrosion traces, around the inter-dendritic regions was recorded here, while the absence of pits also makes it difficult to propose a suggested corrosion mechanism.

Finally, the observation of the cross-section of MoTaNbVTi alloy by Scanning Electron Microscopy (Figure 9) verifies the exemption of the dendritic (Spectrum 2) and inter-dendritic (Spectrum 3) areas from signs of degradation, testifying this way that no evidence of corrosion was spotted. Toward this direction, at the boundaries of the cross-section (Spectrum 1), the relatively low presence of oxygen and other elements of the Hank solution was recorded, which in combination with the presence of the five basic alloying additives, once again underlines its excellent performance against surface degradation phenomena.

This finding is further verified by the findings of the quantitative elemental analysis of Figure 10 which do not indicate the presence of any corrosion traces on the crosssection of the material under consideration. Consequently, no obvious corrosion signs could be identified in the system, which could be directed towards the formulation of a relevant corrosion mechanism.

This clue is probably related to the fact that Mo atoms adsorbed on the surface of the active metal (most commonly $\mathrm{MoO}_{4}{ }^{2-}$ ) reduce the dissolution of the metal atoms, while improving the material's corrosion resistance. In the same direction, $\mathrm{V}$ element can also form a passive film, enhancing the sample's response to pitting corrosion [25]. Therefore, MoTaNbVTi system did not proved to be susceptible to either pericrystalline or pitting corrosion, as further supported by electrochemical data and Scanning Electron Microscopy observation.
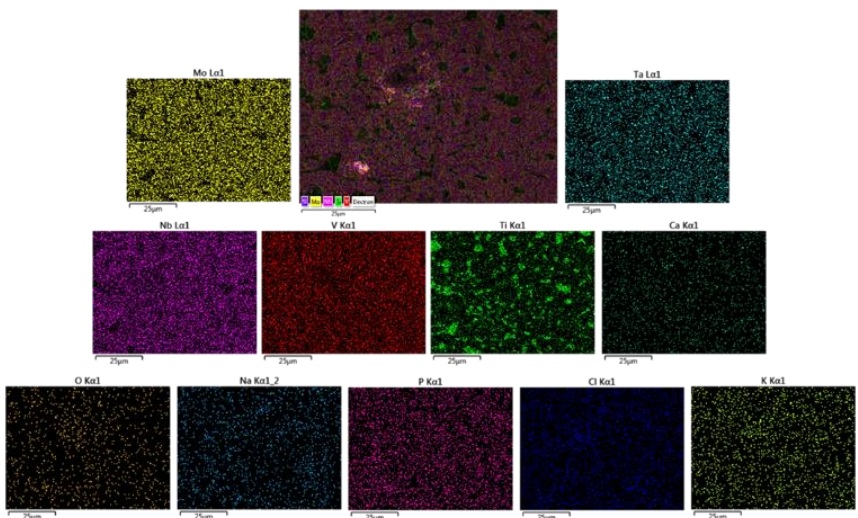

Figure 8. Quantitative EDX mapping analysis of the surface of the corroded MoTaNbVTi system in Hank solution
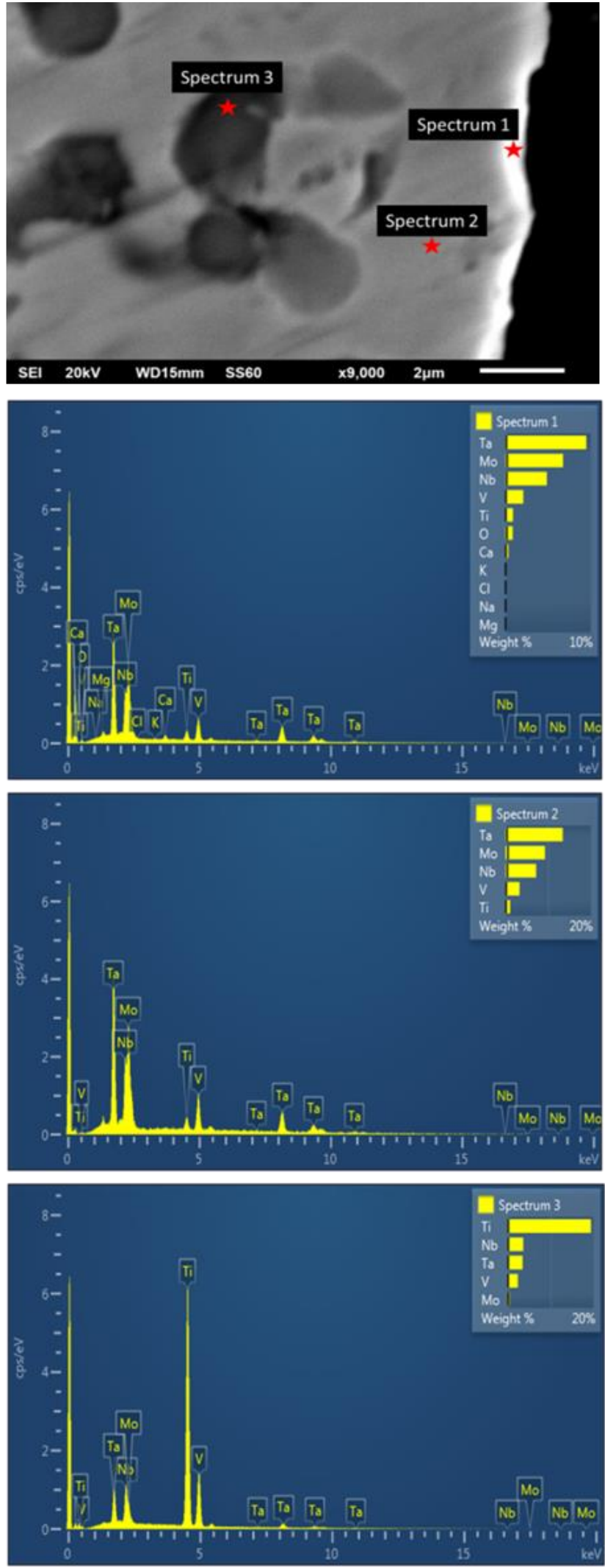

Figure 9. Scanning Electron Microscopy image and elemental point EDX Analysis of the cross-section of the corroded MoTaNbVTi system in Hank solution

Finally, as derived by the Tafel equation calculations, both systems presented a slow corrosion kinetics, regarding the derived corrosion current estimations. Actually, as tabulated in Table 2, in $3.5 \mathrm{wt} . \% \mathrm{NaCl}$ solution, the alloy performed a value of $i_{\text {corr }}=0.026 \pm 0.0011 \mathrm{~mA} / \mathrm{cm}^{2}$, while in Hank solution this value further declined to $\mathrm{i}_{\text {corr }}=0.0078 \pm 0.0008 \mathrm{~mA} / \mathrm{cm}^{2}$. 
These extremely low values are in a complete agreement with the rest experimental findings, indicating the alloy's excellent performance in both corrosive environments.
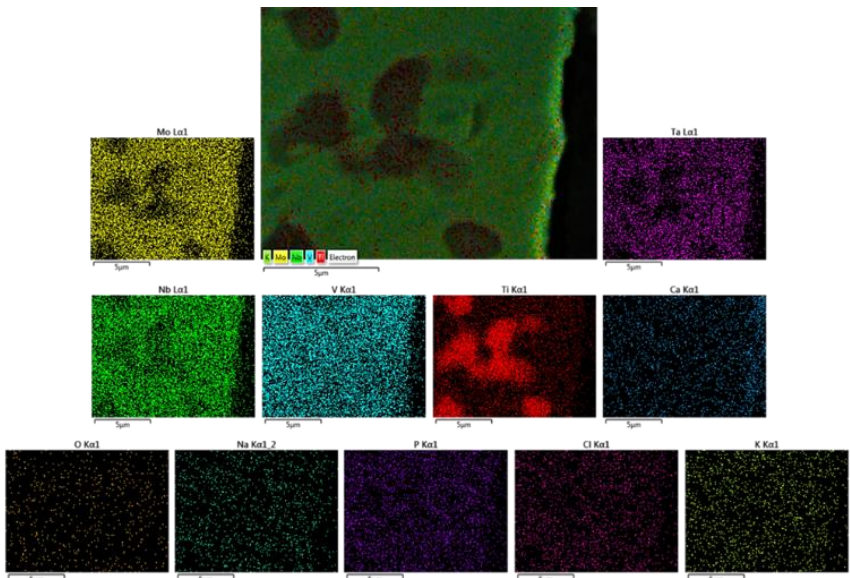

Figure 10. Quantitative EDX mapping analysis of the crosssection of the corroded MoTaNbVTi system in Hank solution

Table 2. Comparative values of corrosion quantities resulting from Tafel equation (for $-100 \mathrm{mV}$ ) regarding MoTaNbVTi HEA in sea water and Hank solution

\begin{tabular}{ccc}
$\begin{array}{c}\text { Calculated } \\
\text { values }\end{array}$ & $\begin{array}{c}3.5 \text { wt.\% NaCl } \\
\text { solution }\end{array}$ & Hank solution \\
$\mathrm{i}_{\text {corr }}\left(\mathrm{mA} / \mathrm{cm}^{2}\right)$ & $0.026 \pm 0.0011$ & $0.0078 \pm 0.0008$ \\
$\mathrm{E}_{\text {corr }}(\mathrm{mV})$ & $-619.73 \pm 19$ & $-599.18 \pm 49$ \\
$\mathrm{E}_{\text {corr,rev }}(\mathrm{mV})$ & $-694.41 \pm 17$ & $-602.12 \pm 45$ \\
$\mathrm{R}^{2}$ & $0.9995 \pm 0.079$ & $0.9987 \pm 0.064$ \\
\hline
\end{tabular}

\section{CONCLUSIONS}

MoTaNbVTi HEA was evaluated in two different media, namely sea water and Hank solution. From the polarization curve analysis in a $3.5 \mathrm{wt} \% \mathrm{NaCl}$, the alloy was found susceptible to local corrosion. Its surface was hardly affected by the presence of the corrosive environment, while only in isolated areas of the surface some oxidized layers of sodium chloride salts were detected. Surprisingly, no selective corrosion along the inter-dendritic regions was recorded, and only the presence of sodium chloride on the surface of the sample in the form of a network was developed in random sites. Regarding Hank solution, some initial speculations have been raised as to the possible susceptibility of the alloy to local forms of corrosion, but due to the small extent of the negative hysteresis loop, these have not been fully confirmed. The examined surface along the dendritic arms as well as in the inter-dendritic space did not show any sign of corrosion. The absence of pericrystalline corrosion traces, was also recorded, while the absence of pits was a limiting factor for the formulation of any proposed corrosion mechanism. In general, MoTaNbVTi proved to be an exceptional candidate concerning its corrosion behavior, with respect to its future demanding application field.

\section{REFERENCES}

[1] Yeh, J.W. (2006). Recent progress in high-entropy alloys. Ann. Chim. - Sci. Mat., 38: 227-232.
https://doi.org/10.4028/www.scientific.net/AMR.631632.227

[2] Cantor, B. (2014). Multicomponent and high entropy alloys. $\quad$ Entropy, 16(9): 4749-4768. https://doi.org/10.3390/e16094749

[3] Zhang, Y., Zuo, T.T., Tang, Z., Gao, M.C., Dahmen, K.A., Liaw, P.K., Lu, Z.P. (2014). Microstructures and properties of high-entropy alloys. Prog. Mater. Sci., 61: 1-93. https://doi.org/10.1016/j.pmatsci.2013.10.001

[4] Jin, X., Bi, J., Zhang, L., Zhou, Y., Du, X., Liang, Y., Li, B. (2018). A new $\mathrm{CrFeNi}_{2} \mathrm{Al}$ eutectic high entropy alloy system with excellent mechanical properties. J. Alloy Compd., 770: 655-661. https://doi.org/10.1016/j.jallcom.2018.08.176

[5] Haas, S., Manzoni, A.M., Krieg, F., Glatze, U. (2019). Microstructure and mechanical properties of precipitate strengthened high entropy alloy $\mathrm{Al}_{10} \mathrm{Co}_{25} \mathrm{Cr}_{8} \mathrm{Fe}_{15} \mathrm{Ni}_{36} \mathrm{Ti}_{6}$ with additions of hafnium and molybdenum. Entropy, 21(2): 169-183. https://doi.org/10.3390/e21020169

[6] Yang, Z., Wang, Z., Wu, Q., Zheng, T., Zhao, P., Zhao, J., Chen, J. (2019). Enhancing the mechanical properties of casting eutectic high entropy alloys with Mo addition. Appl. Phys. A, 125: 208. https://doi.org/10.1007/s00339019-2506-Z

[7] Xu, X.D., Chen, S.Y., Ren, Y., Hirata, A., Fujita, A., Liaw, P.K., Chen, M.W. (2019). Temperature-dependent compression behavior of an $\mathrm{Al}_{0.5} \mathrm{CoCrCuFeNi}$ highentropy alloy. Materialia, 5: 100243. https://doi.org/10.1016/j.mtla.2019.100243

[8] Kumar, S., Patnaik, A., Kumar Pradhan, A., Kumar, V. (2019). Room temperature wear study of $\mathrm{Al}_{0.4} \mathrm{FeCrNiCo}_{\mathrm{x}}$ $(\mathrm{x}=0,0.25,0.5,1.0 \mathrm{~mol})$ high-entropy alloys under oil lubricating conditions. J. Mater. Res., 34(5): 841-853. https://doi.org/10.1557/jmr.2018.499

[9] Shi, X., Wang, C., Huang, M., Cui, H. (2019). Microstructure and wear resistance property of $\mathrm{AlFeCrNiMo}$ coatings by plasma cladding. Mater. Res. Express, 6(10): 106537. https://doi.org/10.1088/20531591/ab3753

[10] Müller, F., Gorr, B., Christ, H.J., Müller, J., Butz, B., Chen, H., Kauffmann, A., Heilmaier, M. (2019). On the oxidation mechanism of refractory high entropy alloys. Corros. $\quad$ Sci., 108161. https://doi.org/10.1016/j.corsci.2019.108161

[11] Huang, D., Lu, J., Zhuang, Y., Tian, C., Li, Y. (2019). The role of $\mathrm{Nb}$ on the high temperature oxidation behavior of $\mathrm{CoCrFeMnNb}_{\mathrm{x}} \mathrm{Ni}$ high-entropy alloys. Corros. $\quad$ Sci., 108088. https://doi.org/10.1016/j.corsci.2019.07.012

[12] Karati, A., Guruvidyathri, K., Hariharan, V.S., Murty, B.S. (2019). Thermal stability of AlCoFeMnNi highentropy alloy. Scripta Mat., 162: 465-467. https://doi.org/10.1016/j.scriptamat.2018.12.017

[13] Yen, C.C., Lu, H.N., Tsai, M.H., Wu, B.W., Lo, Y.C., Wang, C.C., Chang, S.Y., Yen, S.K. (2019). Corrosion mechanism of annealed equiatomic $\mathrm{AlCoCrFeNi}$ triphase high-entropy alloy in $0.5 \mathrm{M} \mathrm{H}_{2} \mathrm{SO}_{4}$ aerated aqueous solution. Corros. Sci., 157: 462-471. https://doi.org/10.1016/j.corsci.2019.06.024

[14] Jin, X., Gu, X., Quan, F., Ran, X., Zhang, K., Mao, A. (2019). CoCrFeMnNi high-entropy alloy powder with excellent corrosion resistance and soft magnetic property prepared by gas atomization method. Materialwiss. Werkstofftech., $\quad$ 50(7):

837-843. 
https://doi.org/10.1002/mawe.201800095

[15] Jayaraja, J., Thinaharana, C., Ningshena, S., Mallikaa, C., Kamachi Mudali, U. (2017). Corrosion behavior and surface film characterization of TaNbHfZrTi high entropy alloy in aggressive nitric acid medium. Intermetallics, $\quad 89$ : 123-132. https://doi.org/10.1016/j.intermet.2017.06.002

[16] Tang, Z., Huang, L., He, W., Liaw, P.K. (2014). Alloying and processing effects on the aqueous corrosion behavior of high-entropy alloys. Entropy, 16(2): 895-911. https://doi.org/10.3390/e16020895

[17] Qiu, Y., Gibson, M.A., Fraser, H.L., Birbilis, N. (2015). Corrosion characteristics of high entropy alloys. Mater. Sci. Tech-lond., 31(10): 1235-1243. https://doi.org/10.1179/1743284715Y.0000000026

[18] Poulia, A., Georgatis, E., Karantzalis, A. (2019). Evaluation of the microstructural aspects, mechanical properties and dry sliding wear response of MoTaNbVTi refractory high entropy alloy. Met. Mater. Int., 1-12. https://doi.org/10.1007/s12540-019-00283-6

[19] Hsu, Y.J., Chiang, W.C., Wu, J.K. (2005). Corrosion behavior of $\mathrm{FeCoNiCrCu}_{\mathrm{x}}$ high-entropy alloys in $3.5 \%$ sodium chloride solution. Mat. Chem. Phys., 92(1): 112117. https://doi.org/10.1016/j.matchemphys.2005.01.001

[20] Wang, W., Qi, W., Xie, L., Yang, X., Li, J., Zhang, Y. (2019). Microstructure and corrosion behavior of $(\mathrm{CoCrFeNi})_{95} \mathrm{Nb}_{5}$ high-entropy alloy coating fabricated by plasma spraying. Materials, 12(5): 694-706. https://doi.org/10.3390/ma12050694

[21] Ayyagari, A., Hasannaeimi, V., Grewal, H.S., Arora, H., Mukherjee, S. (2018). Corrosion, erosion and wear behavior of complex concentrated alloys: A review. Metals, 8(8):
603-643. https://doi.org/10.3390/met8080603

[22] Xiang, C., Zhang, Z.M., Fu, H.M., Han, E.H., Zhang, H.F., Wang, J.Q. (2019). Microstructure and corrosion behavior of $\mathrm{AlCoCrFeNiSi}_{0.1}$ high-entropy alloy. Intermetallics, 114 : 106599. https://doi.org/10.1016/j.intermet.2019.106599

[23] Shang, X.L., Wang, Z.J., Wu, Q.F., Wang, J.C., Li, J.J., Yu, J.K. (2019). Effect of Mo addition on corrosion behavior of high-entropy alloys $\mathrm{CoCrFeNiMo}_{x}$ in aqueous environments. Acta Metall. Sin., 32(1): 41-51. https://doi.org/10.1007/s40195-018-0812-7

[24] Wei, L., Wang, Z., Wu, Q., Shang, X., Li, J., Wang, J. (2019). Effect of Mo element and heat treatment on corrosion resistance of $\mathrm{Ni}_{2} \mathrm{CrFeMo}_{x}$ high-entropy alloy in $\mathrm{NaCl}$ solution. Acta Metall. Sin., 55(7): 840-848. https://doi.org/10.11900/0412.1961.2018.00558

[25] Li, J., Yang, X., Zhu, R., Zhang, Y. (2014). Corrosion and serration behaviors of $\mathrm{TiZr}_{0.5} \mathrm{NbC}_{\mathrm{r} 0.5} \mathrm{~V}_{\mathrm{x}} \mathrm{Mo}_{\mathrm{y}}$ high entropy alloys in aqueous environments. Metals, 4(4): 597-608. https://doi.org/10.3390/met4040597

\section{NOMENCLATURE}

BSE
$E_{b}$
$E_{\text {corr }}$
$E_{\text {corr,rev }}$
EDX
HEAs
$i_{\text {corr }}$
$R^{2}$

Backscattered Electron Breakaway potential, $\mathrm{mV}$ Corrosion potential for the forward polarization, $\mathrm{mV}$ Corrosion potential for the reverse polarization, $\mathrm{mV}$ Energy Dispersion Spectroscopy High Entropy Alloys Current density, $\mathrm{mA} / \mathrm{cm}^{2}$ Standard deviation 